\title{
YAYINCILIK SEKTÖRÜNDE TELİF HAKLARININ MUHASEBE BOYUTU*
}

\section{Ali Haydar GÜNGÖRMÜŞa Ahmet FIRAT ${ }^{b}$}

Örnek Olay (Vak'a) Tahlili

(Case Analysis)
Muhasebe ve Vergi

Uygulamaları Dergisi

Kasim 2019; 12 (3): 731-744

\section{öz}

Bu çalışmanın amacı; yayıncılık sektöründe önemli bir konu olan telif haklarının muhasebe boyutunun ortaya konularak telif ödeme şekillerinin gösterilmesi, telif ödemelerinin hesaplanması, telif ödemeleri ile ilgili özellikli hesapların ve telifle ilgili özellikli muhasebe kayıtlarının yapılış esaslarının açıklanmasıdır.

Fikri mülkiyet haklarından olan telif hakları, Ülkemizde önceden beri genel hukuk içinde "gayri maddi haklar" içinde düşünülmüştür. Türk Vergi kanunları da genellikle bu kavramı kullanmaktadir.

İşletme eser sahibine telif hakkını üç farklı yolla ödeyebilir bunlar; satış miktarı üzerinden telif, üretim miktarı üzerinden telif veya tek seferde ödenen teliftir. Telifin hesaplanma şekline göre farklı muhasebe kayıtları yapılmakta ve ortaya çıkan telif giderleri hesaplanma şekline göre dönemsel gider veya üretim gideri olarak muhasebeleştirilmektedir.

Telif giderlerinin hesaplanma şekline göre dönemsel veya üretim gideri olarak kaydedilmesi işletmenin dönem kâr ve zararı üzerinde değişikliğe sebep olurken işletme için en verimli olan telif anlaşması satış üzerinden yapılan anlaşmalardır. İşletmeler telif hakkını satın aldıkları bir eseri yurt içinde veya yurt dışında bir başka firmaya satarak gelir edebilirler.

Anahtar Sözcükler: Telif hakkı, Muhasebe, Yayıncılık Sektörü.

JEL Kodları: M40, M41.

APA Stili Kaynak Gösterimi:

Güngörmüş, A.H., Fırat, A. (2019). Yayıncılık Sektöründe Telif Haklarının Muhasebe Boyutu. Muhasebe ve Vergi Uygulamalarl Dergisi. 12 (3), 731-744.

* Makalenin gönderim tarihi: 15.04.2019; Kabul tarihi: 10.06.2019, iThenticate benzerlik oranı \%16

${ }^{a}$ Dr.-SMMM, a.h.gungormus@gmail.com,ORCID:0000-0001-8404-1464.

b SMMM-Bağımsız Denetçi, maliduyuru77@gmail.com, ORCID: 0000-0002-8596-5084.

Muhasebe ve Vergi Uygulamaları Dergisi 


\title{
THE ACCOUNTING ASPECT OF COPYRIGHTS IN PUBLISHING SECTOR
}

\begin{abstract}
The aim of this study is to present the accounting aspect of in meabs of asserting the methods of payment, to calculate the copyright payments, and to explain the special accounts of copyright payments and fundamentals of special accounting records. Copyrights, which are of intellectual properties, hace been classified in our country in common law as part of "intangible rights". Turkish Tax Laws also generally use this concept. An enterprise can pay copyrights to an author in three different ways. These are as follows: copyrights according to the sales amount, according to the output, and according to lump sum. Different accounting records are used according to the calculation of the copyrights and the copyright occurred is recognized as periodic expense or production cost according to the expenses. While recording copyright expenses as periodic or production expenses causes a change in periodic income and loss of an enterprise, the most profitable copyright convention is that made according to the sales amount. Enterprises can generate incomes by selling the copyrights of a work they already acquired to another domestic or international company.
\end{abstract}

Keywords: Copyright, Accaunting, Publishing Sector.

JEL Codes: M40, M41.

\section{GíRiș}

Günümüzün modern toplumlarını ayakta tutan temel dinamiklerin başında kuşkusuz "bilgi" unsuru gelmektedir. Globalleşmeyle birlikte yaşanan köklü yapısal değişimde, endüstri toplumunun stratejik kaynağı olan "sermaye" yerini "bilgi "ye terk ederken, "endüstri toplumu" yerini tamamen farklı bir yapıda olan "bilgi toplumuna bırakmaktadır. Yaşanan bu süreçte, neredeyse beşeri maddi ilişkilerin tamamının sanal ortamda yürütülmesine olanak sağlayan ve bunu insanoğlunun hizmetine sunan enformasyon toplumunun taleplerini karşılamaya yönelik bilgi üreten ünitelerin giderek önem kazanmakta olduğu yadsınmaz bir vakıadır.

Gelişen teknoloji ve küreselleşen dünyada bilgi devrimi ile birlikte hem yazılı hem de görsel alanda ortaya konulan ürün veya eserlerin dolaşımı kolaylaşmıştır. $\mathrm{Bu}$ anlamda ortaya konulan eserlerin eser niteliği taşıyıp taşmadığı konusunda bazen tartışmalar yaşanmaktadır. Söz konusu bu dolaşımda ortaya çıkarılan bu ürünlerin ticarileştirilmeleri konusunda karmaşık bir hal ortaya çıkmıştır. Bu eserlerin ticarileştirilmeleri ile birlikte eser sahiplerine ödenen teliflerin vergisel ve muhasebe boyutu ile ilgili uygulamalar söz konusu olmuştur.

Fikir ve sanat eserlerinin ortaya çıkması ile yasal düzenlemeler yanında uluslararası düzenlemelerin de yapılması aslında bunların teşvik ve korunması ile ilgilidir. Bu eserleri korumak sadece fikir hukuku açısından değil vergi hukuku açısından da çeşitli düzenlemeler yapılmıştır. Eser sahibinin hakkının korunması ve teşvik edilmesi ile ilgili olarak Gelir

Muhasebe ve Vergi Uygulamaları Dergisi 
Vergisi Kanunda çeşitli düzenlemeler yapılmıştır. Diğer kanunlarda herhangi açıklayıcı düzenlemeler yapılmadığı gözükmektedir.

Telif hakları ile ilgili Gelir vergisi açısından değerlendirme yapılırken Serbest Meslek faaliyeti açısından 193 sayılı Gelir Vergisi Kanunun 65. Maddesinde ve Gelir Vergisi Kanunu 18. Maddesinde vurgu yapılmaktadir. Ve ayrıca Gelir Vergisi Kanunu 82. Maddesinin 4. Bendinde Arızi kazançlar kısımlarında yer almaktadır. Telif hakkının eser niteliği taşıyabilmesi için 5846 Sayılı Fikir ve Sanat Eserleri kanunu kapsamında değerlendirmesi gerekir.

Telif Hakk1; bir fikir veya sanat eserini yaratan kişinin, bu eserden doğan haklarının hepsi olarak tanımlanmıştır. 5846 sayılı Fikir ve Sanat Eserleri Kanunu'nun 1. maddesinde ise eser; "Sahibinin hususiyetini taşıyan ve ilim ve edebiyat, musiki, güzel sanatlar veya sinema eserleri olarak sayılan her nevi fikir ve sanat mahsulleri” olarak ifade edilmiştir (FSEK,Md:1).

Türkiye'de telif hakları olarak kabul edilen bilim, edebiyat, müzik, güzel sanatlar ve sinema eserleri Fikir ve Sanat Eserleri Kanunu (FSEK) ile korunmaktadır. FSEK'te bir fikri ürünün eser olarak kabul edilebilmesi için iki şart aranmaktadır bunlar:

- FSEK'te kabul edilen eser türlerinden birine dâhil olmalıdır (objektif şart). Sadece fikir aşamasında kalan, hayata geçirilmeyen fikri ürünler koruma kapsamı dişındadır

- Eser sahibinin hususiyetini taşımalıdır (sübjektif şart). Hususiyet ile sahibinden özellikler taşıyan, yani sahibinden sadır olan ürünler kastedilmektedir (http://www.fikrimulkiyet.com).

\section{TELIF UYGULAMALARINDA ÖZELLIKLII MUHASEBE HESAPLARI}

İşletme eser sahibine telif hakkını üç farklı yolla ödeyebilir bunlar;

-Satış miktarı üzerinden ödenen telifler,

-Üretim miktarı üzerinden ödenen telifler,

-Tek seferde ödenen telifler.

Telifin hesaplanma şekline göre farklı muhasebe kayıtları yapılmakta ve ortaya çıkan telif giderleri hesaplanma şekline göre dönemsel gider veya üretim gideri olarak muhasebeleştirilmektedir. $\mathrm{Bu}$ noktada telif ödemelerinin kayıtlara alınmasında özellikli bilanço ve gelir tablosu hesapları kullanılmaktadır. 


\section{1. Özellikli Bilanço Hesapları}

\section{Maddi Olmayan Duran Varlıklar}

Herhangi bir fiziksel varlığı bulunmayan ve işletmenin belli bir şekilde yararlanmayı beklediği aktifleştirilen giderler ile belirli koşullar altında hukuken himaye gören haklar ve şerefiyelerin izlendiği hesap gruplarıdır (Gökgöz, 2015:159).

260.01 Eser Telif Haklarl: Yurt içinde ve yurt dışında bulunan kişi ve kurumlardan bir bedel ödenerek alınan telif hakları maliyet bedeli ile bu hesaplarda aktifleştirilerek kayıt altına alınır.

\section{Birikmiş Amortismanlar}

Maddi olmayan duran varlık bedellerinin, kullanılabilecekleri süre içerisinde yok edilebilmesini sağlamak amacıyla kullanılan hesaplardır.

268.01 Telif Hakkı Birikmiş Amortismanlar Hesabı: Yurt içinde ve yurt dışında bulunan kişi ve kurumlardan bir bedel ödenerek alınan telif hakları için ayrılan amortismanlar, ilgili gider hesapları karşılığında bu hesaba alacak olarak kaydedilirler. Telif Hakları, 333. Seri nolu VUK Genel Tebliğinin 55. Bölümüne uygun olarak 15 yılda $\%$ 6,66 oran üzerinden amorti edilerek giderleştirilirler.

\section{Ödenecek Vergi ve Fonlar}

İşletmenin ekonomik faaliyetlerde bulunmasının bir sonucu ilgili mali mevzuat uyarınca mükellef veya sorumlu sıfatı ile işletmenin kendisine, personeline ve üçüncü kişilere ilişkin olarak ödenmesi gereken vergi, resim, harç ve fonların izlendiği hesaplardır (Kishalı,2016:134).

360.10 Yurtiçi Stopaj Ödemesi: Yurtiçinden Alınan Telifleri ile ilgili olarak ödenmesi gereken Vergi, resim, harçların tahakkuk ettirilmesi gereken olay ve işlemler için ortaya çıktıkça hesaplar alacak olarak kayıt edilir.

360.20 Yurtdışı Stopaj Ödemesi: Yurtdışından Alınan Telifleri ile ilgili olarak ödenmesi gereken Vergi, resim, harçların tahakkuk ettirilmesi gereken olay ve işlemler için ortaya çıktıkça hesaplar alacak olarak kayıt edilir.

360.302 Nolu KDV Ödemesi: İşletmenin hem yurtiçinden hem de yurtdışından almış olduğu telif hizmetleri için direkt sorumluları adına ödemesi gereken Katma Değer Vergisi ödemelerinin izlendiği hesaptır.

\section{2. Özellikli Gelir Tablosu ve Maliyet Hesapları}

\section{Brüt Satışlar}

İşletmenin esas faaliyetleri çerçevesinde satılan mal veya hizmetler karşılığında alınan ya da tahakkuk ettirilen toplam tutarları kapsar. Satılan mal ve hizmetler ile ilgili sübvansiyonlar satış tarihindeki vade farkları,

Muhasebe ve Vergi Uygulamaları Dergisi 
ihracat ile ilgili dönem içinde ortaya çıkan farklar, vergi iadeleri brüt satışlar içinde gösterilir (Akdoğan ve Sevilengül,2007:571).

600.01 Yurt İçi Telif Satışları: İşletme telif hakkını satın aldığı bir eserin telif hakkını yurt içindeki bir başka yayın evine sattığı takdirde buradan elde ettiği gelirin kaydedildiği hesaplardır.

601.01 Yurtdışı Telif Satışlart: İşletmenin Yurtdışından elde ettiği telif satışlarına istinaden tahakkuk ettirdiği gelirleri gösteren hesaptır.

\section{Genel Üretim Gideri}

Üretim için ortaya çıkmakla birlikte; direkt ilk madde ve malzeme, direkt işçilik dışında kalan ancak mamul ve hizmet giderleri ile ilişkili olan giderlerin tamamını kapsayan giderlerdir (Elmac1, Güngörmüş ve Gümüş, 2002).

730.10 Yurtiçi Telif Giderlerimiz: İşletmenin yurtiçinden temin ettiği ve baskı üzerinden verdiği teliflerin gider olarak takip edildiği gider kalemidir.

730.20 Yurtdışı Telif Giderlerimiz: İşletmenin yurtdışından temin ettiği ve baskı üzerinden verdiği teliflerin gider olarak takip edildiği gider kalemidir.

\section{Pazarlama Satış Dağıtım Giderleri}

Mamulün stoklara verildiği ve hizmetin tamamlandığı andan itibaren bu mal ve hizmetin alıcılara teslimine kadar yapılan tüm giderler bu hesapta takip edilir (Güngörmüş, Ayçiçek, vd, 2013:111).

760.10 Yurtiçi Telif Giderleri: İşletmenin yurtiçinden temin edilen ve satış üzerinden verilen teliflerin gider olarak kayıt edildiği gider kalemidir.

760.20 Yurtdışı Telif Giderleri: İşletmenin yurtdışından temin edilen ve satış üzerinden verilen teliflerin gider olarak kayıt edildiği gider kalemidir.

760.40.01 Yurtiçi Telif Hak Amortismanı Gideri: Yurtiçinden temin edilen teliflerin amortisman kayıtlarının tutulduğu gider kalemidir.

760.41.02 Yurtiçi Telif Hak Amortismanı Gideri: Yurtiçinden temin edilen teliflerin amortisman kayıtlarının tutulduğu gider kalemidir.

\section{TELIF HESAPLAMA YÖNTEMLERI VE ÖZELLIKLI MUHASEBE KAYITLARI}

Yayınc1lık sektöründe telif ödeme yöntemleri üç farklı şekilde hesaplanarak muhasebeleştirilmektedir bunlar:

- Satış miktarı üzerinden hesaplanan ve ödenen telif hakları,

- Baskı miktarı üzerinden hesaplanan ve ödenen telif hakları,

- Tek seferlik telif hakkı (eserin satın alınması) üzerinden hesaplanan ve ödenen telif hakları. 
Telif ödeme yöntemlerindeki farklılıklar muhasebe kayıtlarına da yansımakta telif yöntemine göre bazen dönemsel gider olarak muhasebeleştirilirken bazen üretim gideri olarak kayıtlara alınmakta, bazen de aktifleştirilmektedir.

\subsection{Satış Adedi Üzerinden Telif Hesaplaması ve Muhasebe Kayıtları}

Yayıncı kuruluş eser sahibi ile kitabın satış adedi üzerinden telif ücreti ödeme konusunda anlaşma yaptığ 1 takdirde bu telif "satış adedi üzerinden telif" olarak kabul edilir. Yayıncı kuruluşun eser sahibine kitap satış adedi üzerinde yapmış olduğu telif ödemeleri dönemsel gider olarak kabul edilir ve "pazarlama satış ve dağıtım gideri” olarak muhasebeleştirilir.

\section{Örnek:}

AHG Yayıncılık Tic. A.Ş firması "Maliyet Muhasebesi "' isimli eser için telif bedeli olarak "satış miktarı üzerinden " $\mathrm{X}$ isimli yazar ile anlaşma yapmıştır. Anlaşma gereği telif alacağı kitabın satış fiyatı üzerinden $\% 8$ oranında olacaktır.

Tablo-1: Satış Üzerinden Telif Hesaplaması

\begin{tabular}{|l|r|}
\hline Satış Adedi & 15.000 Adet \\
\hline Kitap Üzeri Fiyat KDV Hariç & $5 \mathrm{TL}$ \\
\hline Satış Toplamı & $15.000 \times 5=75.000 \mathrm{TL}$ \\
\hline Telif Oranı ( \%8) & $75.000 \times 8 / 100=6.000 \mathrm{TL}$ \\
\hline Net Ödeme & $6.000 \mathrm{TL}$ \\
\hline Stopaj (\%17) & $7.229 \times 00 / 0,83=7.229 \mathrm{TL}$ \\
\hline Stopajı Tutarı & $7.229 \times 1.229 \mathrm{TL}$ \\
\hline Sorumlu Sıfatıyla KDV (\%18) & \\
\hline
\end{tabular}

\begin{tabular}{|l|r|r|}
\hline ..........01.12.xxxx....... & BORÇ & ALACAK \\
\hline $\begin{array}{l}\text { (Yo.10 Pazarlama Satış ve Dağıtım Telif Giderleri) } \\
\text { 191 İndirilecek KDV }\end{array}$ & $7.299,00$ & \\
360.10 Yurtiçi Stopaj Ödemesi & & \\
360.30 2 Nolu KDV Ödemesi & & $1.301,00$ \\
$320 \ldots . .$. Yazar & & $6.000,00$ \\
\hline
\end{tabular}

Muhasebe ve Vergi Uygulamaları Dergisi 


\subsection{Baskı Miktarı Üzerinden Telif Hesaplaması ve Muhasebe Kayıtları}

Yayıncı kuruluş eser sahibi ile basılan kitap sayısı üzerinden telif ücreti ödeme konusunda anlaşma yaptığı takdirde bu telif "baskı miktarı üzerinden telif” olarak kabul edilir. Yayıncı kuruluşun eser sahibine basılan kitap sayısı üzerinde yapmış olduğu telif ödemeleri üretim gideri olarak kabul edilir ve "genel üretim gideri" olarak muhasebeleştirilir.

\section{Örnek:}

AHG Yayıncılık Tic. A.Ş firması 'Şirketler Muhasebesi ' isimli eser için telif bedeli olarak "Baskı miktarı üzerinden " yazar ile anlaşma yapmıştır. Anlaşma gereği telif alacağı baskı miktarı üzerinden $\% 8$ oranında hesaplanmıştır. Kitabın Baskı miktarı 15.000 adettir. Satış Birim fiyatı KDV 5 TL'dir.

Tablo-2: Bask1 Miktarı Üzerinden Telif Hesaplamas1

\begin{tabular}{|l|r|}
\hline Baskı Miktarı & 15.000 Adet \\
\hline Kitap Üzeri Fiyat KDV Hariç & $5 \mathrm{TL}$ \\
\hline Satış Toplamı & $15.000 \times 5=75.000 \mathrm{TL}$ \\
\hline Telif Oranı ( \%8) & $75.000 \times 8 / 100=6.000 \mathrm{TL}$ \\
\hline Net Ödeme & $6.000 \mathrm{TL}$ \\
\hline Stopaj (\%17) & $6.000 / 0,83=7.229 \mathrm{TL}$ \\
\hline Stopajı Tutarı & $7.229 \times 0,17=1.229 \mathrm{TL}$ \\
\hline Sorumlu Sıfatıyla KDV (\%18) & $7.229 \times 0,18=1.301 \mathrm{TL}$ \\
\hline
\end{tabular}

\begin{tabular}{|l|r|r|}
\hline .............01.12.xxxx........ & BORÇ & ALACAK \\
\hline 730.10 Genel Üretim Gideri & $7.299,00$ & \\
191 İndirilecek KDV & $1.301,00$ & \\
360.10 Yurtiçi Stopaj Ödemesi & & $1.229,00$ \\
360.30 2 Nolu KDV Ödemesi & & $1.301,00$ \\
$320 \ldots .$. Yazar & & $6.000,00$ \\
& & \\
\hline
\end{tabular}

\subsection{Eser Hakkının Satın Alınmasından Dolayı "Tek Seferlik "Telif Hesaplaması ve Muhasebe Kayıtları}

Yayıncı kuruluş eser sahibi ile bir kereye mahsus olarak tek seferde telif ücreti ödeme konusunda anlaşma yaptığı takdirde bu telif "tek seferlik telif" olarak kabul edilir. Yayıncı kuruluşun eser sahibine tek seferde yapmış 
olduğu telif ödemeleri haklar hesabında aktifleştirilir ve 333. Seri nolu VUK Genel Tebliğinin 55. Bölümüne uygun olarak 15 yılda yüzde 6,66 oran üzerinden amortisman ayrilır.

\section{Örnek:}

AHG Yayıncılık Tic. A.Ş firması 'Banka Muhasebesi "' isimli eseri için telif bedeli olarak " Tek Seferlik Telif " yazar ile anlaşma yapılmıştır. Yazar ile Tek seferlik telif ücreti olarak 7.500.- TL ödenecektir.

Tablo-3: Tek Seferde Ödeme Üzerinden Telif Hesaplaması

\begin{tabular}{|l|r|}
\hline Net Ödeme & $7.500 \mathrm{TL}$ \\
\hline Stopaj (\%17) & $7.500 / 0,83=9.036 \mathrm{TL}$ \\
\hline Stopajı Tutarı (\% 17) & 9.036 X0,17=1.536 TL \\
\hline Sorumlu Sıfatıyla KDV (\%18) & $9.036 \times 0,18=1.627 \mathrm{TL}$ \\
\hline
\end{tabular}

\begin{tabular}{|c|c|c|}
\hline .............01.12.xxxx........ & BORÇ & ALACAK \\
\hline 260 Haklar Hesab1 & $9.036,00$ & \\
191 İndirilecek KDV & $1.627,00$ & \\
360.10 Yurtiçi Stopaj Ödemesi & & \\
360.30 2 Nolu KDV Ödemesi & & $1.536,00$ \\
$320 \ldots$. Yazar & & $7.627,00$ \\
& & \\
\hline ............01.12.xxxx........ & BORÇ & ALACAK \\
\hline 230 Genel Üretim Gideri & & \\
& & 601,79 \\
\hline
\end{tabular}

\subsection{Yurtdışından Telif Alınması İle İlgili Muhasebe Kaydı}

Yurtdışında mukim kişi ve kurumlardan alınan telif hakları Kurumlar Vergisi 30. Maddesi gereğince dar mükellef kapsamına girmektedir. Bakanlar Kurulu Kararınca iç mevzuat gereğince \% 20 oranında Kurumlar Vergisi kesintisi yapılması gerekmektedir. İşletmeler stopaj ile ilgili avantaj sağlamak amacıyla kişi ve kurumlardan ilgili makamlardan alınmak üzere Mukimlik (İkametgâh veya vergi faaliyet belgesi) belgesi alınırsa Çifte vergilendirme Önleme anlaşması gereğince öncelikli olarak bu anlaşma hükümleri uygulanması gerekmektedir.

Yurtdışında alınan telif hakları çifte vergilendirmeyi önleme anlaşması hükümlerine göre gayri maddi hak hükmünde olduğu için stopaj kesintisi yapılması gerekmektedir. Katma değer vergisi açısından baktığımızda faydalanma Türkiye'de olduğu için sorumlu sıfatıyla Katma değer vergisi

Muhasebe ve Vergi Uygulamaları Dergisi 
ödemesi yapılması gerektedir. Vergi usul açısından baktığımızda yapılan bu faaliyeti gider pusulası, karşı taraftan fatura ile belgelemek uygun olacaktır.

\section{Örnek:}

$\mathrm{ABC}$ işletmesi Almanya mukimi bir kurumdan X eser hakkının telif hakkını satın almıştır. Anlaşma gereği 1.000.- TL üzerinden telif ödeyecektir. Almanya'da kurumun mukimlik belgesi vardır. Kurum normal stopaj üzerinden $\% 20$ kesinti yapması gerekir. Mukimlik belgesi olduğu için bu oran $\% 10$ düşmektedir. Diğer $\% 10 \mathrm{k}$ sım Almanya makamlardan telif hakkını satan kurum tarafından ilgili vergi dairesine ödenecektir.

Tablo-4: Yurt Dışından Telif Alınması

\begin{tabular}{|l|r|}
\hline Net Ödeme Yazar & $1.000 \mathrm{TL}$ \\
\hline Stopajı Tutarı (\% 10) & $1.000 / 0,90=1.111 \mathrm{TL}$ \\
\hline GV Stopajı ( \% 10) & $1.111 \times 0,10=111 \mathrm{TL}$ \\
\hline Sorumlu Sıfatıyla KDV & $1.111 \times 0,18=199 \mathrm{TL}$ \\
\hline
\end{tabular}

\begin{tabular}{|l|r|r|}
\hline ............01.12.xxxx........ & \multicolumn{1}{|c|}{ BORÇ } & ALACAK \\
\hline 260 Haklar Hesab1 & $1.111,00$ & \\
191 İndirilecek KDV & 199,00 & \\
360.10 Yurtiçi Stopaj Ödemesi & & 111,00 \\
360.30 2 Nolu KDV Ödemesi & & 199,00 \\
320 .... Yazar & & $1.000,00$ \\
& & \\
\hline
\end{tabular}

Yukarıdaki yapılan muhasebe kayıtlarında yurtdışı telif alımı olduğu için \% 20 olması gereken stopaj oranı \%10 uygulanmış olup ilgili vergi dairesine ödenecektir. Sorumlu sıfatıyla KDV açısından yapılan işlemde hizmetten Türkiye'de faydalanıldığı için sorumlu sifatıyla KDV beyan edilip 1Nolu KDV ile indirim konusu yapılacak ve Sorumlu Sifatıyla Katma değer vergisi vergi dairesine ödenecektir.

\begin{tabular}{|c|r|r|}
\hline ............01.12.xxxx........ & BORÇ & ALACAK \\
\hline 230 Genel Üretim Gideri & 73,99 & \\
268 Birikmiş Amortismanlar & & 73,99 \\
& & \\
\hline
\end{tabular}

Muhasebe ve Vergi Uygulamaları Dergisi 
333. Seri nolu VUK Genel Tebliğinin 55. Bölümüne uygun olarak 15 yılda yüzde 6,66 oran üzerinden amorti edilecektir.

\subsection{Yurtiçi Telif Satış ile İlgili Muhasebe Kaydı}

İşletme telif hakkını satın aldığı bir eserin telif hakkını yurt içindeki bir başka yayın evine sattığı takdirde buradan elde ettiği geliri "Yurt İçi Satışlar" hesabında gösterir. Bu satışla ilgili olarak kitabın ilk sahibine bir ödeme söz konusu ise telif gideri "Pazarlama ve Satış ve Dağıtım Gideri”" hesabında gösterilir.

\section{Örnek:}

AHG Yayınevi X isminde bir yazardan almış olduğu " Genel Muhasebe" isimli eserin telifini Türkiye sınırları içinde Güneş Yayınevine telif karşılığ 1 olarak 5.900.- TL KDV dâhil (100.000 adet basım izinli eseri ) satmıştır. İki yayınevi aralarında sözleşme yapmışlardır. Sözleşmenin damga vergisini yayın hakkını alan Fırat Yayınevi üstlenmiştir. Eser sahibi ile Nehir Yayınevi arasındaki anlaşmaları gereği bu eserin maliyeti olarak yazara bu satış üzerinden yüzde 10 üzerinden telif verecektir.

Tablo-5: Yurt İçi Telif Satışı Telif hesaplaması

\begin{tabular}{|c|c|}
\hline Net Ödeme & 5.000.-TL X $10 / 100=500 \mathrm{TL}$ \\
\hline Brüt Telif (\% 17) & $500 / 0,83=602,40 \mathrm{TL}$ \\
\hline Sorumlu Sifatıyla KDV (\% 18) & $602,40 \times 18 / 100=108,43 \mathrm{TL}$ \\
\hline Stopaj (\%17) & $602,40 * 17 / 100=102,40 \mathrm{TL}$ \\
\hline
\end{tabular}

\begin{tabular}{|l|r|r|}
\hline .............01.12.xxxx........ & BORÇ & ALACAK \\
\hline $\begin{array}{l}\text { 120 Alıcılar Hesab1 } \\
\text { (AHG Yayın Evi) }\end{array}$ & 5.900 & \\
600 Yurt İçi Satışlar & & \\
391 Hesaplanan KDV & & 9000 \\
& & \\
\hline
\end{tabular}

Muhasebe ve Vergi Uygulamaları Dergisi 


\begin{tabular}{|l|r|r|}
\hline .............01.12.xxxx........ & BORÇ & ALACAK \\
\hline $\begin{array}{l}\text { (Yo.10 Pazarlama Satış ve Dağıtım Gideri } \\
\text { (Yuri Telif Giderleri) }\end{array}$ & 602,40 & \\
360.10 Yurtiçi Stopaj Ödemesi & & 108,43 \\
360.30 2 Nolu KDV Ödemesi \\
$320 \ldots .$. Yazar & & 102,40 \\
& & 500,00 \\
& & \\
\hline
\end{tabular}

\subsection{Yurtdışı Telif Satışı ile İlgili Muhasebe Kaydı}

İşletme telif hakkını satın aldığı bir eserin telif hakkını yurt dışındaki bir başka yayın evine sattığı takdirde buradan elde ettiği geliri "Yurt dışı Satışlar" hesabında gösterir. Bu satışla ilgili olarak kitabın ilk sahibine bir ödeme söz konusu ise telif gideri "Pazarlama ve Satış ve Dağıtım Gideri" hesabında gösterilir. Satış yurtdışına olduğu için herhangi bir KDV söz konusu olmayacaktır. Çünkü teslim yurtdışınadır. Yurtdışına teslimde KDV söz konusu değildir.

\section{Örnek:}

Nar yayınevi " Mehnet Erdal"' isimli yazarın "Muhasebe "' isimli kitabını Almanya' da mukim olan X yayın evine telif olarak 10.00 adet baskısı için 50.000.- TL X yayınevine devir etmiştir. Nar Yayınevi bu satışa istinaden Yazara yüzde 12 üzerinden telif vermiştir.

Tablo-6: Yurt Dışı Telif Satışı

\begin{tabular}{|l|r|}
\hline Net Ödeme & 50.000 X 12/100=6.000 TL \\
\hline Brüt Telif (\% 17) & $6.000 / 0,83=7.228,91 \mathrm{TL}$ \\
\hline Sorumlu Sıfatıyla KDV & $7.228,91 \times 18 / 100=1.301,20 \mathrm{TL}$ \\
\hline Stopaj (\%17) & $7.228,91 \times 17 / 100=1.228,91 \mathrm{TL}$ \\
\hline
\end{tabular}

\begin{tabular}{|c|r|r|}
\hline .............01.12.xxxx........ & BORÇ & ALACAK \\
\hline 120 Alıcılar Hesab1 & $50.000,00$ & \\
601 Yurt Diş1 Satışlar & & $50.000,00$ \\
& & \\
\hline
\end{tabular}


Ali Haydar GÜNGÖRMÜŞ - Ahmet FIRAT

\begin{tabular}{|c|c|c|}
\hline .............01.12.xxxx........ & BORÇ & ALACAK \\
\hline 760.10 Pazarlama Satış ve Dağıtım Gideri & $7.228,91$ & \\
191 İndirilecek KDV & $1.301,20$ & \\
360.10 Yurtiçi Stopaj Ödemesi & & $1.128,91$ \\
360.30 2 Nolu KDV Ödemesi & & $1.301,20$ \\
$320 \ldots .$. Yazar & & $6.000,00$ \\
& & \\
\hline
\end{tabular}

\section{SONUÇ}

Gelişen teknoloji ve küreselleşen dünyada bilgi devrimi ile birlikte hem yazılı hem de görsel alanda ortaya konulan ürün veya eserlerin dolaşımı kolaylaşmıştır. $\mathrm{Bu}$ anlamda ortaya konulan eserlerin eser niteliği taşıyıp taşmadığı konusunda bazen tartışmalar yaşanmaktadır. Söz konusu bu dolaşımda ortaya çıkarılan ürünlerin ticarileşmesi ile birlikte hem vergisel hem de muhasebe alanında farklılıklar ve yeni uygulamalar söz konusu olmuştur.

Fikir ve sanat eserlerinin ortaya çıkması ile yasal düzenlemeler yanında uluslararası düzenlemelerin yapılması hep bunların teşvik ve korunması ile ilgilidir. Bu eserleri korumak için sadece fikir hukuku açısından değil vergi hukuku açısından da çeşitli düzenlemeler yapılmıştır. Eser sahibinin hakkının korunması ve teşvik edilmesi ile ilgili olarak Gelir Vergisi Kanunda çeşitli düzenlemeler yapılmıştır. Diğer kanunlarda ise herhangi açıklayıcı düzenlemeler yapılmadığı gözükmektedir.

Fikri mülkiyet haklarından olan telif hakları, Ülkemizde önceden beri genel hukuk içinde "gayri maddi haklar" içinde düşünülmüştür. Türk Vergi kanunları da genellikle bu kavramı kullanmaktadır.

Telif hakları ile ilgili Gelir vergisi açısından değerlendirme yapılırken Serbest Meslek faaliyeti açsından 193 sayılı Gelir Vergisi Kanunun 65. Maddesinde ve Gelir Vergisi Kanunu 18. Maddesinde vurgu yapılmaktadir. Ve ayrıca Gelir Vergisi Kanunu 82. Maddesinin 4. Bendinde Arızi kazançlar kısımlarında yer almaktadır. Telif hakkının eser niteliği taşıyabilmesi için 5846 Sayılı Fikir ve Sanat Eserleri kanunu kapsamında değerlendirmesi gerekir.

Telif haklarının muhasebe uygulamalarında işletmeler için en uygun olan telif sözleşmesi "satış miktarı " üzerinden yapılan anlaşmalardır. İşletme telifi eserin satışı üzerinden ödediği için gelir ortaya çıktıktan sonra bir ödeme yapacaktır. Eserler satılmadığı sürece işletme için ekstra bir telif gideri söz konusu olmaz. 
Bask1 üzerinden ve tek seferde verilen teliflerde ise satılmayan ve stokta kalan ürünlerin veya mamullerin teliflerin ödemesi herhangi bir gelir elde edilmeden yapilacak ve ilgili eser satılmasa bile buna ait telif gideri ödendiği için finansal olarak firmanın aleyhine bir durum oluşacaktır. Yine Tek seferlik telif ödemelerinde de ürünün veya mamulün ne kadarlık satılacağ1 belli olmadan peşin olarak yazara ödeme yapılması eserin satılamaması durumunda işletme için ekstra bir maliyet olarak gerçekleşecektir.

Yurtdışı telif ödemelerinde ise dikkat edilmesi gereken ise Mukimlik belgesinin karşı firmadan veya şahıstan istenmiş olması gerekmektedir. Mukimlik belgesi ilgili ülkede ticari faaliyete bulunduğuna dair olan bir ikametgâh belgesidir. Çoğu firma bu belgeyi almakta zorlanmaktadır. $\mathrm{Bu}$ belge olmadan vergilendirme işlemlerinde yanlışlıklar yapılmaktadır. Bunları önlemek için bu belgeyi aldıktan sonra vergi kısmı ile ilgili işlemlerin yapılması uygundur. Türkiye'de ise bu belgeyi Maliye Bakanlığından ilgili vergi dairesi müdürlüğünden talep edilerek alınmaktadır.

\section{KAYNAKÇA}

Akdoğan, N. ve Sevilengül, O. (2007). Tekdüzen Muhasebe Sistemi Uygulamas1, Gazi Kitabevi, Ankara.

Ayçiçek, F., Güngörmüş, A.H., Atalay, B., Boyar, E., Kurulu, R. (2013). Dönemsonu Muhasebe İşlemleri, Sürat Üniversite yayınları, İstanbul.

Beşiroğlu, A. (2006). Fikir Hukuku Dersleri İstanbul.

Gökgöz, A. (2015). Genel Muhasebe, Ekin Kitabevi, Bursa

Elmac1, O. Güngörmüş, A.H., Gümüş, Y. (2002). Maliyet Muhasebesi, Ekspres matbaas1, 2002.

http://www.fikrimulkiyet.com/index.php?option=com_content\&task=view\& $\mathrm{id}=21 \&$ Itemid $=74$

http://www.resmigazete.gov.tr/eskiler/2006/12/20061230-40.pdf

http://www.telifhaklari.gov.tr

Kishal1, Y. (2016). Tekdüzen Hesap Sistemi ve Çözümlü Muhasebe Problemleri, Beta Basım Yayım, İstanbul.

Özdemir, M. (2002) "http://www.alomaliye.com"

Özderyol, T. A. (2006). Fikir ve Sanat Eserleri Kanunu'nda Düzenlenen Suçlar, İstanbul

193 sayılı Gelir Vergisi Kanunu "http://mevzuat.basbakanlik.gov.tr

Muhasebe ve Vergi Uygulamaları Dergisi 
213 Sayıl1 Vergi Usul Kanunu "http://www.mevzuat.gov.tr/

3065 Sayılı Katma Değer Vergisi Kanunu "http://www.mevzuat.gov.tr/" 5520 sayıl1 Kurumlar Vergisi Kanunu "http://www.mevzuat.gov.tr/

5846 Say1l Fikir ve Sanat Eserleri kanunu;

"http://mevzuat.basbakanlik.gov.tr 